\title{
The problem of mephedrone in Europe: Causes and suggested solutions
}

\section{Legal status}

Based on the report of the European Commission on 3 August 2010, on 2 December 2010 the Council of the European Union decided to submit mephedrone to control measures and criminal sanctions provided for by national legislations throughout the European Union (20101759/UE) [1]. In accordance with the Act of 10 June 2010 amending the Act on Counteracting Drug Addiction (Journal of Laws of 2010, No. 143, item 962), mephedrone was included in the 1-P group of psychotropic substances [2]. The British Act on Psychoactive Substances was introduced in 2016 to eliminate new psychoactive substances [3]. Unfortunately, this did not solve the problem of increased hospitalisation of patients using mephedrone. In recent years, a rapid increase in the number of admissions of patients on a mephedrone binge has been observed in various countries $[4,5]$. The number of fatal poisonings associated with mephedrone abuse has, unfortunately, also been increasing. Declared deaths after taking mephedrone were caused by too high blood pressure resulting in a stroke. The fact that nearly 100 percent of people combine mephedrone with other psychoactive substances is also noteworthy [6]. Due to the strong addictive potential of this drug, a large number of people are repeatedly hospitalised.

\section{Easy mephedrone access}

Despite the introduction of individual acts, mephedrone is still easily available. It can be ordered via the internet, which should not happen. There are a lot of online stores offering mephedrone. This is due to insufficient legal solutions. New analogues of mephedrone appear all the time. In 2010, the NRG-1 and NRG-2 products that were the successors of illegal mephedrone were analysed in the United Kingdom. Seventy percent of tested samples still contained mephedrone and its illegal derivatives [7]. The research also shows that a large number of young people buy mephedrone at social events. Winstock et al. conducted a survey of 947 people who had ever taken mephedrone. It turned out to be the sixth most widely used psychoactive drug in Great Britain [8]. In various European countries, mephedrone was advertised and sold as a chemical reagent, bath salt, plant fertiliser or as a fragrance freshener for vacuum cleaners. These products contained an annotation that the product was unfit for human consumption. This is an additional factor causing the increased hospitalisation of patients taking mephedrone. Many websites offer modified mephedrone, explaining that it is still an original product and shows almost identical activity as the unmodified mephedrone [9]. Katarzyna Malinowska-Sempruch, director of the Global Drug Policy Program at the Open Society Institute, said that legal highs were sold online in 21 European countries and in stores in 17 countries [10].

\section{How to reduce the problem of mephedrone?}

One way to reduce the number of patients admitted to hospitals due to mephedrone abuse is to improve education on the subject. Until now, this type of education was negligible. Among other things, there are too few classes for young people on this topic. Current education involves scaring society with the consequences of mephedrone abuse. The results are very often the opposite. Namely, some people become even more curious and try to buy and consume mephedrone. The more they are scared, the more they may become interested. This is evidenced by special internet forums (hyperreal.info) in which users write thousands of posts saying they used mephedrone out of curiosity, which increased after the introduction of the laws. Future education should include even more detailed teaching about new psychoactive substances, including mephedrone. It should include a series of different lessons, for example for young people, in which various aspects of mephedrone and its new derivatives are discussed. These aspects should include topics such as the effects of the drug on the human body, the effects of its abuse, its addictive potential and the danger associated with combining mephedrone with other psychoactive substances.

Another very important way to reduce the hospitalisation of patients using mephedrone is to block websites through which they can buy this psychoactive substance. Reducing the number of websites advertising mephedrone would greatly reduce the problem of mephedrone. It is sufficient to look through many search engines on the internet to find out that blocking this type of website would significantly reduce the problem. Future online control of emerging new websites suspected of advertising mephedrone also seems to be desirable. In this way, the frequency of such website visits by people planning to use mephedrone or its derivatives would decrease. Instead, there should be as many websites on the internet as possible that would describe the psychological and medical aspects of mephedrone. This would increase public awareness of the problem of mephedrone. These websites should describe issues related to the consumption of 
mephedrone in a simple and accessible way for different age groups. Another way to reduce the problem of mephedrone in European countries is to run media campaigns on the subject. In this way, people's knowledge about the harmfulness of mephedrone would increase, and thus the frequency of hospitalisation of patients taking this psychoactive substance would decrease. The scientific community should also be involved in conducting educational campaigns to explain how serious the problem of mephedrone abuse is in today's medicine. The dissemination of medical knowledge based on preclinical as well as clinical trials seems to be very valuable.

We hope that the topic presented in this article will help reduce the problem of the increased number of patients using mephedrone in today's Europe. Changes should be made as soon as possible, otherwise the problem will expand as it did between 2010 and 2018.

\section{References}

[1] Council Decision. Council decision of 2 December 2010 on submitting 4methylmethcathinone (mephedrone) to control measures (2010/759/EU). 2010. http://www.emcdda.europa.eu/attachements.cfm/ att_134870_EN_Council_Decision_2010_759_EU_2_December_2010.pdf.

[2] The Law of 10 June 2010 Amending the Act on Counteracting Drug Addiction] (in Polish). Polish Internet Database System of Legal Acts. 10 June 2010. Retrieved 2010-08-25. http://prawo.sejm.gov.pl/isap.nsf/DocDetails.xsp? id=WDU20101430962.

[3] UK Parliament. Psychoactive substances act. 2016. . (Accessed 22 March 2016) http://services.parliament.uk/bills/201516/psychoactivesubstances.html.

[4] Hockenhull J. Mephedrone use is increasing in London. Lancet 2016;387 (10029):1719-20.

[5] Pantano F, Tittarelli R, Mannocchi G, Pacifici R, di Luca A, Busardò FP, et al. Neurotoxicity induced by mephedrone: an up-to-date review. Curr Neuropharmacol 2017;15(5):738-49.
[6] Busardò FP, Kyriakou C, Napoletano S, Marinelli E, Zami S. Mephedrone related fatalities: a review. Eur Rev Med Pharmacol Sci 2015;19(19):3777-90.

[7] Brandt SD, Sumnall HR, Measham F, Cole J. Analyses of second-generation' legal highs' in the UK: initial findings. Drug Test Anal 2010;2(8):377-82.

[8] Winstock AR, Mitcheson LR, Deluca P, Davey Z, Corazza O, Schifano F. Mephedrone, new kid for the chop? Addiction 2011;106(1):154-61.

[9] Glennon RA. Bath salts, mephedrone, and methylenedioxypyrovalerone as emerging illicitdrugs that will need targeted therapeutic intervention. Adv Pharmacol 2014;69:581-620.

[10] Sempruch-Malinowska K. Shaping drug policy in Poland. Int J Drug Policy $2016 ; 31: 32-8$.

M. Ordak*

Department of Pharmacodynamics, Centre for Preclinical Research and Technology (CePT), Medical University of Warsaw, Poland

T. Nasierowski

Department of Psychiatry, Medical University of Warsaw, Poland

Department of Pharmacodynamics, Centre $f$ and Technology (CePT), Medical University of Warsaw, Poland

* Corresponding author at: Department of Pharmacodynamics, Centre for Preclinical Research and Technology (CePT), Medical University of Warsaw, St. Banacha 1B, 02-097, Warsaw, Poland. E-mail address: mordak@wum.edu.pl (M. Ordak).

Received 28 August 2018

Available online 29 October 2018 